This paper is published as

McCabe, BY, Tran, V, Ramani, J, 2005, "Construction prequalification using data envelopment analysis", Canadian Journal of Civil Engineering, 32:183-193

\title{
CONSTRUCTION PREQUALIFICATION USING DATA ENVELOPMENT ANALYSIS
}

\author{
Brenda McCabe ${ }^{1}$, Associate Professor, Department of Civil Engineering, University of \\ Toronto, Toronto, ON M5S 1A4 \\ Viet Tran, Research Assistant, Department of Civil Engineering, University of Toronto, \\ Toronto, ON M5S 1A4 \\ Joseph Ramani, Research Assistant ${ }^{2}$, Department of Civil Engineering, University of \\ Toronto, Toronto, ON M5S 1A4
}

\begin{abstract}
Contractor prequalification is essential in most construction projects and the process has been performed by many different methods in practice. Data envelopment analysis (DEA) had been recognized as a useful technique to prequalify contractors by assigning relative efficiency scores. DEA, however, usually requires a large amount of data and has not been fully developed to achieve reliable results. An enhanced contractor prequalification model using DEA was developed together with a methodology for determining a "practical frontier" of best contractors. The established practical frontier can be used as a regional performance standard for the owner in prequalification and as improvement guidelines for contractors.
\end{abstract}

Key Words: contractor prequalification; construction engineering; data envelopment analysis; practical frontier

\section{INTRODUCTION}

Prequalification is a screening process applied to contractors before tendering to reduce the risk of project failure. Most prequalification models use some form of a weighted scoring system where the contractors are scored according to weighted criteria that are finally summed to produce a single value. The problems inherent in this decision-making procedure are the biases and additive assumptions introduced in the development of the weights and the evaluation process.

The authors considered that prequalification is similar to benchmarking in that the objective of the process is to identify the best performers and the distance between the remaining contractors and those best performers. The three objectives of this research were:

1. To establish an improved contractor prequalification model using DEA

2. To develop an adaptation of the P-DEA framework for the construction situation

3. To define a procedure that can be used to identify the practical frontier of contractors.

\footnotetext{
${ }^{1}$ Corresponding author: Ph. 416-946-3505; Fax 416-978-5054; mccabeb@civ.utoronto.ca

${ }^{2}$ Currently Project Engineer, Ontario Power Generation
} 
This paper develops and demonstrates the evaluation method called data envelopment analysis (DEA) (typically used for benchmarking) to discriminate between contractors in the prequalification process. DEA is a nonparametric linear programming framework that produces a single measure of efficiency for each unit relative to its peers. Advancements in DEA processes are tested and compared, including a final modification of our own.

All prequalification systems have the same basic steps (Russell and Skibniewski 1988): develop the criteria, gather contractor data, verify data, apply contractor data to criteria, and decide whether to prequalify the contractor. Most of the companies and public agencies that perform prequalification have their own model, and the continued interest in the prequalification process by industry is reflected in the array of systems that have been developed through research. The existing prequalification models employ frameworks that vary from simple weighted scoring systems to complex mathematical formulations.

Qualifier-1 (Russell and Skibniewski 1990) employs a dimensional weighting procedure that produces aggregate weighted ratings of candidate contractors based on data obtained from questionnaires. Equation 1 presents the linear formulation used in the model, and best represents models used most commonly in industry.

$$
A R_{k}=\sum_{i=1}^{n} W_{i}\left[\sum_{j=1}^{m_{i}}\left(w_{i j}\right)\left(R_{i j k}\right)\right] \quad i=1, \ldots, \mathrm{n} \quad j=1, \ldots, m_{i}
$$

where: $A R_{k}=$ Aggregate weighted rating of candidate contractor $k, n=$ Number of composite decision factors (CDF), $W_{i}=$ Weight of CDF $i$ (ranges from 0 to 1.0, sum of all $W_{i}=1$ ), $m=$ Number of decision factors (DF) describing the CDF, $w_{i j}=$ Weight of the DF $j$, describing CDF $i$ (ranges from 0 to 1.0, sum of all $w_{i j}=1$ ), $R_{i j k}=$ Rating of DF $j$ describing CDF $i$ (ranges from 1 to 10) for candidate contractor $k$

Russell et al. (1990) developed Qualifier-2 shortly afterward adding a knowledgebased expert system and a 3-stage decision hierarchy where contractors must meet each level of the decision criteria to proceed. This ensured that high scores in one, perhaps less important area, did not hide a low score in another category.

AbouRizk and Chehayeb (1995) developed the Hypertext Decision Support Prequalification (HDSP) model primarily to help decision makers assign weights for the different criteria. Using multi-attribute decision making (MADM), factors are compared two at a time rather than attempting to give importance weights to a larger number of factors at once. The system of pair wise comparisons is solved using eigenvectors. In Gong's (1999) Contractor Prequalification Process, a three-stage model combines the hierarchical framework of Qualifier-2 and the MADM of the HDSP model.

Several systems not based on weighted scores have been developed. Fuzzy set theory was applied in conjunction with Monte Carlo simulation to enhance the contractor evaluation process (Elton et al. 1994). A utility model for comparing fuzzy numbers developed by Juang et al. (1987) was used, resulting in a Contractor Prequalification Ranking Index ranging from 0 to 1 : the higher the index, the greater the perceived capability of the contractor. The primary disadvantages of the model are the number of parameters required, and the complexity of the framework. Cluster analysis was used to group the contractors with similar attributes (Holt 1996) and the best subset would be invited to tender. Hanna et al. (1997) developed a system based on neural networks. The major disadvantage of neural networks is the requirement for a large amount of data, which may be difficult in this context due to the 
reluctance of many contractors to provide data, and the generally small set of contractors prequalifying for any single project.

Prequalification criteria vary from model to model and are usually specific to the project; however, the most common criteria appear in most models in some form. Table 1 shows criteria used in 8 different models listed from the most common to the least common, where:

1 = Public owner's projects, Qualifier-1 (Russell and Skibniewski 1990)

2 = Private owner's projects, Qualifier -1 (Russell and Skibniewski 1990)

$3=$ Artificial Neural Network model (Hanna et al. 1997)

4 = Fuzzy Sets model (Elton et al. 1997)

5 = Canada (CCDC $11-1996)$

6 = Saudi Arabia and United Kingdom (Bubshait and Al-Gobali 1996)

7 = Japan (Paulson and Aki 1980)

$8=$ Australia (Liston 1994)

Table 1: Comparison of Prequalification Criteria (Gong 1999)

\begin{tabular}{|c|c|c|c|c|c|c|c|c|}
\hline \multirow[t]{2}{*}{ Prequalification Criteria } & \multicolumn{8}{|c|}{ Prequalification Model } \\
\hline & 1 & 2 & 3 & 4 & 5 & 6 & 7 & 8 \\
\hline Financial stability & $\mathrm{X}$ & $\mathrm{X}$ & $\mathrm{X}$ & $\mathrm{X}$ & & $\mathrm{X}$ & $\mathrm{X}$ & $\mathrm{X}$ \\
\hline Capacity for assuming new projects & $x$ & $\mathrm{X}$ & $\mathrm{X}$ & $\mathrm{X}$ & & $\mathrm{X}$ & & $\mathrm{X}$ \\
\hline Safety & & $X$ & $\mathrm{X}$ & $x$ & & $\mathrm{X}$ & $\mathrm{X}$ & $X$ \\
\hline Type of contractor $\&$ years in business & $X$ & & & $\mathrm{X}$ & $\mathrm{X}$ & $\mathrm{X}$ & $X$ & $X$ \\
\hline Percentage of work performed & $\mathrm{X}$ & & & $x$ & $x$ & $\mathrm{X}$ & $X$ & $X$ \\
\hline Location & $X$ & $\mathrm{X}$ & & $\mathrm{X}$ & & $X$ & $X$ & $X$ \\
\hline Past performance & $X$ & $X$ & & $\mathrm{X}$ & & $X$ & & $\mathrm{X}$ \\
\hline Management & & $X$ & $\mathrm{X}$ & $\mathrm{X}$ & & $\mathrm{X}$ & & $X$ \\
\hline Bonding & $X$ & $x$ & & $x$ & $\mathrm{X}$ & & & $\mathrm{X}$ \\
\hline Key personnel & & & & $\mathrm{X}$ & $\mathrm{X}$ & $\mathrm{X}$ & $\mathrm{X}$ & \\
\hline Experience & & & $\mathrm{X}$ & $X$ & & $\mathrm{X}$ & & $X$ \\
\hline Failure history & & $X$ & & $\mathrm{X}$ & & $\mathrm{X}$ & $X$ & \\
\hline Equipment resources & & $X$ & & $\mathrm{X}$ & & $\mathrm{X}$ & & $\mathrm{X}$ \\
\hline Workforce resources & & & & $x$ & & $\mathrm{X}$ & $\mathrm{X}$ & $\mathrm{X}$ \\
\hline Annual value of work in 5 years & & & & & $\mathrm{X}$ & $\mathrm{x}$ & $x$ & \\
\hline $3^{\text {rd }}$ party evaluation & $X$ & & & $\mathrm{X}$ & & & & $X$ \\
\hline Similar or related projects completed & & & $\mathrm{X}$ & & $\mathrm{X}$ & & $\mathrm{X}$ & \\
\hline Quality assurance and control program & & & & $\mathrm{X}$ & & $\mathrm{X}$ & & $\mathrm{X}$ \\
\hline References evaluation & & & $\mathrm{X}$ & & & $x$ & & \\
\hline Shareholder information & & & $X$ & & & $\mathrm{X}$ & & \\
\hline Reputation to subs, unions, suppliers & & & $\mathrm{X}$ & & & & & $X$ \\
\hline Time and budget performance & & & & $\mathrm{X}$ & & & & $X$ \\
\hline Principal projects in 5 years & & & & & $\mathrm{X}$ & & $\mathrm{X}$ & \\
\hline Litigation history & & & & $\mathrm{X}$ & & & & \\
\hline Insurance performance & & & & & & & $\mathrm{X}$ & \\
\hline
\end{tabular}

\section{DATA ENVELOPMENT ANALYSIS}

Throughout this paper and consistent with DEA terminology, the term decision-making unit or $D M U$ will refer to the individuals in the evaluation group. In the context of this application, it will refer specifically to contractors. 
In parametric analysis, the objective is to optimize a single regression plane through the data; a single optimized regression equation is assumed to represent the group. DEA, on the other hand, generates a surface called the frontier that follows the peak performers and envelops the remainder (Charnes et al. 1994). Figure 1 illustrates the concepts of the empirical and theoretical production frontiers in a two-dimensional surface to generalize the case of a multi-dimensional surface.

The theoretical frontier represents the absolute maximum possible production that a DMU can achieve in any level of inputs; however, theoretical relationships between input and output parameters to a system are generally difficult to identify and to express mathematically. For this reason, the theoretical frontier is usually unknown. The relative or empirical frontier, which is based upon real DMU is therefore used. The empirical frontier connects all the relatively best DMUs in the observed population. Note that if the performance of all of the observed DMUs is generally poor, then your empirical frontier only gives you the best of a bad lot! The theoretical frontier would clearly indicate that the poor DMUs were indeed poor.

Two efficiency values can be defined for $D M U_{x}$ in Figure 1:

- Absolute Efficiency = A/C

- $\quad$ Relative Efficiency $=A / B$

The DMUs that lie on the empirical frontier have a relative efficiency score of 1.0. Those that lie under this frontier are deemed inefficient and have an efficiency score other than 1.0 .

The four basic DEA models are the Charnes Cooper Rhodes (CCR) model, the Banker Charnes Cooper (BCC) model, the multiplicative model and the additive model. Only the CCR and BCC will be discussed here. These models can be distinguished by the envelopment surface, and the orientation. As shown in

Figure 2, the envelopment surface can take the form of constant-return-to-scale (CRS) or variable-return-to-scale (VRS) as evaluated in the CCR model and the BCC model respectively. The CRS surface is represented by a straight line that starts at the origin and passes through the first DMU that it meets as it approaches the observed population. The models with CRS envelopment surface assume that an increase in inputs will result in a proportional increase in outputs.

Outputs

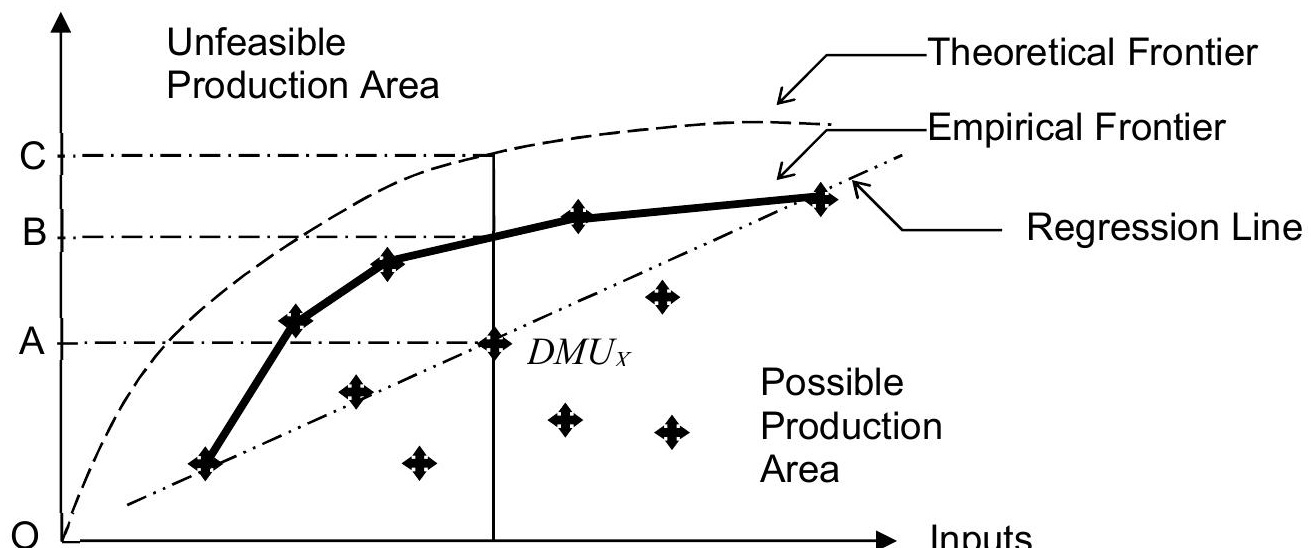




\section{Figure 1: Empirical Frontier \& Theoretical Frontier}

The VRS surface envelops the population by connecting the outermost DMUs, including the one approached by the CRS surface. The VRS model allows an increase in input values to result in a non-proportional increase of output levels - increasing returns to scale (IRS) occur below the point where CRS and VRS meet, and decreasing returns to scale (DRS) above.

The other essential characteristic of DEA models is orientation, which indicates the direction an inefficient DMU approaches the efficient frontier: either an increase in its output levels while maintaining the same level of input (output-oriented), or a decrease in its input while keeping the same output level (input-oriented). Input oriented efficiency scores range between 0 and 1.0 and where as output oriented efficiency scores range between 1.0 and infinity; in both cases, 1.0 is efficient. The output-oriented optimization of $\mathrm{DMU}_{\mathrm{Y}}$ in

Figure 2 is slightly different in that the DMU is not fully enveloped by the surface. In this case, $\mathrm{DMU}_{\mathrm{Y}}$ first approaches the frontier by increasing its output and then by using the "slack" variables to reach the efficient frontier. The VRS surface was used in this research; therefore, only the BCC model will be discussed in detail.

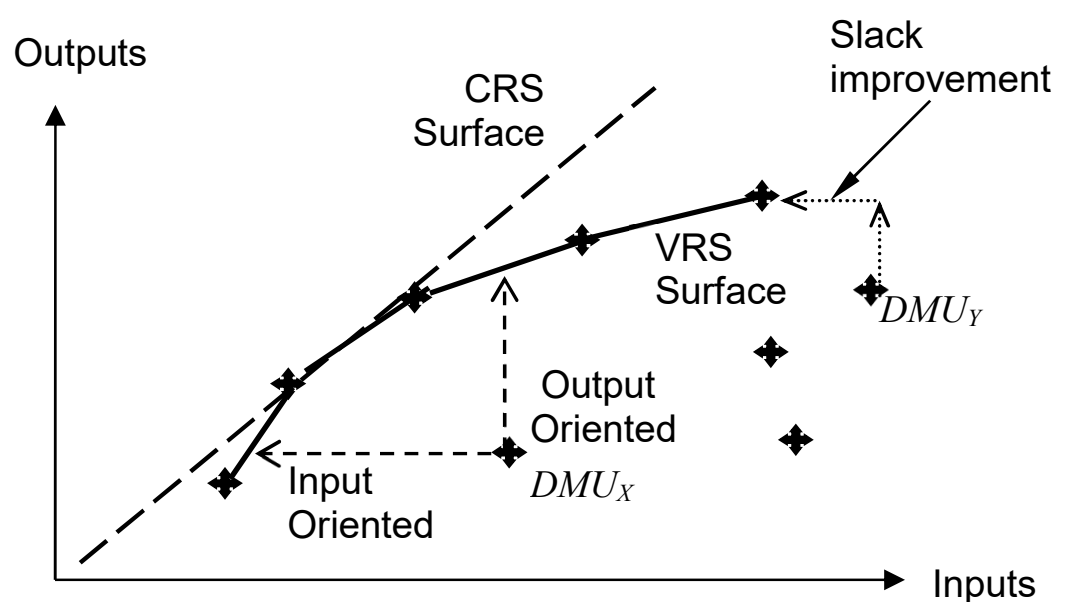

Figure 2: Envelopment Surfaces \& Orientation 


\section{BCC (VRS) Models}

The linear programming system for the BCC input oriented model is given in Equation 2, and the output oriented model in Equation 3 (refer to Charnes et al. 1994 for more detail). The calculations provide a maximal performance measure using piecewise linear optimization on each DMU with respect to the closest observation on the frontier.

$$
\max h_{o}=\sum_{r=1}^{s} u_{r} y_{r o}+u_{o}
$$

such that $\quad \sum_{i=1}^{m} v_{i} x_{i o}=1$

$$
\sum_{r=1}^{s} u_{r} y_{r j}-\sum_{i=1}^{m} v_{i} x_{i j}+u_{o} \leq 0
$$

$i=1, \ldots, m \quad j=1, \ldots, n$

$$
r=1, \ldots, s
$$

$$
u_{r}, v_{i} \geq \varepsilon
$$

[3]

$$
\min \quad q_{o}=\sum_{i=1}^{m} v_{i} x_{i o}+v_{o}
$$

such that

$$
\begin{aligned}
& \sum_{r=1}^{m} u_{r} y_{r o}=1 \\
& \sum_{i=1}^{m} v_{i} x_{i j}-\sum_{r=1}^{s} u_{r} y_{r j}+v_{o} \geq 0 \\
& i=1, \ldots, m \quad j=1, \ldots, n
\end{aligned}
$$

$$
u_{i}, v_{r} \geq \varepsilon \quad r=1, \ldots, s \quad u_{o} \text { free }
$$

where: $x_{i j}$ is the $i^{\text {th }}$ input of the $j^{\text {th }} \mathrm{DMU}, y_{r j}$ is the $r^{\text {th }}$ output of the $j^{\text {th }} \mathrm{DMU}, u_{r}$ and $v_{i}$ are the output and input weight, respectively.

The objective of the function is to obtain the weights that maximize the efficiency of the $\mathrm{DMU}$ under evaluation, $\mathrm{DMU}_{0}$, while limiting the efficiency of all DMUs to less than or equal to 1.0 (for input-oriented models). Variables of this model are the efficiency score and the input/output weights; the inputs and outputs of the DMUs are known.

Charnes, Cooper and Rhodes (1978) recognized the difficulty in seeking a standard set of weights to calculate relative efficiency and that DMUs might value inputs and outputs differently and therefore adopt different weights. They therefore proposed that each DMU should adopt weights that show it in the most favorable light relative to the other DMUs. This flexibility in the weights is both a weakness and strength of this approach. It is a weakness because the judicious choice of weights by a DMU possibly unrelated to the value of any input or output may allow a DMU to appear efficient but it may have more to do with the choice of weights than operational efficiency. This flexibility may also be considered strength, because a DMU that is inefficient with even the most favorable weights cannot argue that the weights are unfair. As that might be, relationships can be incorporated into the model to constrain the weights as deemed appropriate.

It is very important to recognize that the efficiency values produced by DEA are only valid within that particular group of peers. A contractor that is efficient in one group may be quite inefficient when compared to another group. In other words, if a group of very poor 
contractors were evaluated using DEA, you would still have efficient contractors. (As discussed later, developing a practical frontier is one way of addressing this shortcoming.) Further, if the set of DMU is small, then there is little discrimination between them. Consider

Figure 2 where five of the nine DMU are on the efficient frontier. A general rule is that there should be at least three times the DMUs as there are variables (inputs + outputs) in the model (Banker et al. 1984). In the case of contractor prequalification, often there are 10 or fewer contractors to evaluate per contract. This would restrict the number of evaluation variables to three, which is simply too few for a thorough and reliable prequalification. It is, therefore, desirable to identify a standard set of best performers in construction prequalification, i.e. to identify the practical frontier that would act as a fixed framework from which all contractors could be compared.

\section{PRACTICAL FRONTIER IN DEA}

Sowlati (2001) asserted that it may be possible to create a series of artificial DMUs that are equally or more efficient than the best performers, and that these DMUs could be based upon practical improvements of current efficient DMUs judged by expert opinion. From this premise, she developed P-DEA and the practical frontier. The resulting practical frontier is formed mostly by the artificial DMUs, as shown in Figure 3. In essence, the practical frontier improves the empirical frontier, and brings it closer to the theoretical frontier.

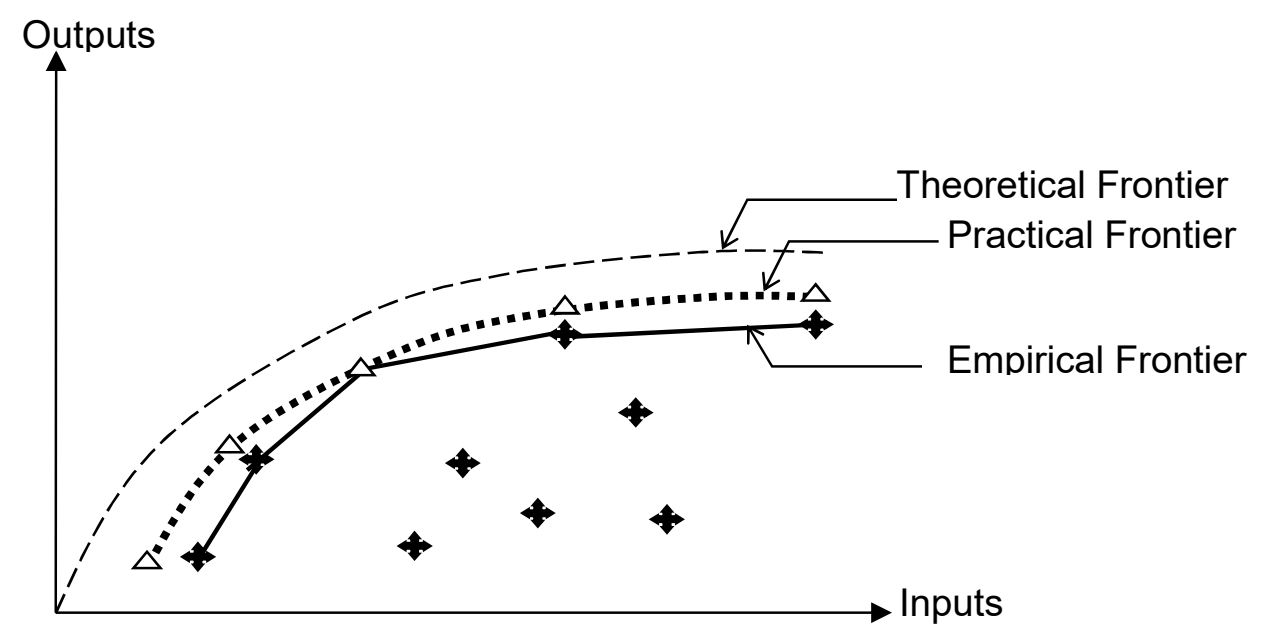

Figure 3: The Theoretical, Practical and Empirical Frontiers (Sowlati 2001)

The procedure has three stages (Sowlati 2001). In Stage-I, conventional DEA, as shown in the input oriented BCC form of Equation 2, is used to evaluate the efficiency of all DMUs and to identify the efficient units. Restrictions on the weights can be applied to increase its discrimination power. 
In Stage-II, expert opinions are obtained on possible efficiency improvements, $\delta$, and on the allowable input/output ranges of efficient DMUs as $L_{x i 0} \leq x_{i 0} \leq U_{x i 0}$ and $L_{y r 0} \leq y_{r 0} \leq U_{y r 0}$. Equation 4 is used to find the efficiency score, the weights $u_{r}$, and $v_{i}$, and inputs and outputs $\tilde{x}_{i o}$, and $\tilde{y}_{r o}$ of the new DMUs; Equation 4 is formed by substituting into Equation 2:

$\begin{array}{llll}\text { the variables: } & \tilde{x}_{i o} \cdot v_{i} & \text { by } \quad p_{r} \\ & \tilde{y}_{r o} \cdot u_{r} & \text { by } \quad q_{i} \\ & L_{x i o} \leq \tilde{x}_{i o} \leq U_{x i o} & \text { by } \quad v_{i} \cdot L_{x i o} \leq q_{i} \leq v_{i} \cdot U_{x i o}, \\ \text { the constraints: } & L_{y r o} \leq \tilde{y}_{r o} \leq U_{y r o} & \text { by } & u_{r} \cdot L_{y r o} \leq p_{r} \leq u_{r} \cdot U_{y r o}\end{array}$

[4]

$$
\begin{aligned}
& \operatorname{Max} \sum_{r=1}^{s} p_{r}+u_{o} \\
& \text { such that } \quad \sum_{i=1}^{m} q_{i}=1 \\
& \sum_{r=1}^{s} u_{r} y_{r j}+u_{o}-\sum_{i=1}^{m} v_{i} x_{i j} \leq 0, \quad \forall j \\
& \sum_{r=1}^{s} u_{r} y_{r o}+u_{o}-\sum_{i=1}^{m} v_{i} x_{i o}=0 \\
& \sum_{r=1}^{s} p_{r}+u_{o}-\sum_{i=1}^{m} q_{i} \geq 0, \\
& \sum_{r=1}^{s} p_{r}+u_{o}-\sum_{i=1}^{m} q_{i}(1+\delta) \geq 0, \\
& v_{i} \cdot L_{x i o} \leq q_{i} \leq v_{i} \cdot U_{x i o}, \quad \forall i \\
& u_{r} . L_{y r o} \leq p_{r} \leq u_{r} . U_{y r o}, \quad \forall r \\
& i=1, \ldots, m \quad j=1, \ldots, n \quad u_{i}, v_{r} \geq \varepsilon \quad r=1, \ldots, s \quad u_{o} \text { free }
\end{aligned}
$$

The addition of constraint \#3, indicated by the dashed box, is a modification to Sowlati's P-DEA formulation. The objective of the formulation is to determine the weights and value of inputs and outputs that maximize the efficiency within an upper limit $(\delta)$ of the DMU under evaluation, which originally had an efficiency score of 1.0. The new DMU developed from it will therefore have an efficiency score within the range of 1.0 and $1.0+\delta$.

Constraint \#2 ensures that the efficiency of other DMUs will not exceed 1.0 with the determined weights. This constraint (\#2), however, allows the DMU under evaluation to have an efficiency score of less than 1.0 and eventually permits the difference in efficiency between the original DMU and the new artificial DMU to be more than $\delta$, the upper limit value. Constraint $\# 3$, therefore, was included to enforce the restriction of $\delta$ by controlling the efficiency score of the original efficient DMU. 
In Stage-III, the model is run again with the real and artificial DMUs and a new set of efficient units is defined, which will consist of some combination of real and artificial DMUs. The inputs and outputs of the artificial DMUs are shown in Equation 5.

$$
\tilde{x}_{i o}{ }^{*}=\frac{q_{i}{ }^{*}}{v_{i}{ }^{*}} \text { and } \tilde{y}_{r o}{ }^{*}=\frac{p_{r}{ }^{*}}{u_{r}{ }^{*}}
$$

Once the practical frontier is established, the requirement to have a minimum number of DMUs to run a reliable model is removed. In fact, the analysis no longer has to be a batch process; it can be run with just a single DMU and the practical frontier. Additionally, this practical frontier could serve as a measure of the quality of contractors vying for the projects of a large owner over time.

\section{METHODOLOGY, CRITERIA SELECTION \& DATA}

The CPM (contractor prequalification model) framework initially developed by Ramani (2000) and modified by Tran (2002) is based on data envelopment analysis (DEA) and provides an evaluating method that is computationally advanced, capable of reducing human and arithmetic bias, and is defensible. The model consists of three stages: (1) bonding capacity; (2) DEA; and (3) rank/short-listing. Figure 4 presents a graphical representation of the model.

Bonding capacity is one of the most important criteria in the prequalification process, but it is not a quantitative variable. Stage 1 of the model eliminates from the process any contractor that is unable to obtain the appropriate bonding for the project. In Stage 2, DEA is applied to evaluate the relative performance of the contractors in the form of efficiency scores. In Stage 3, the efficiency scores are used to rank the contractors. The qualified contractors are then short-listed. 


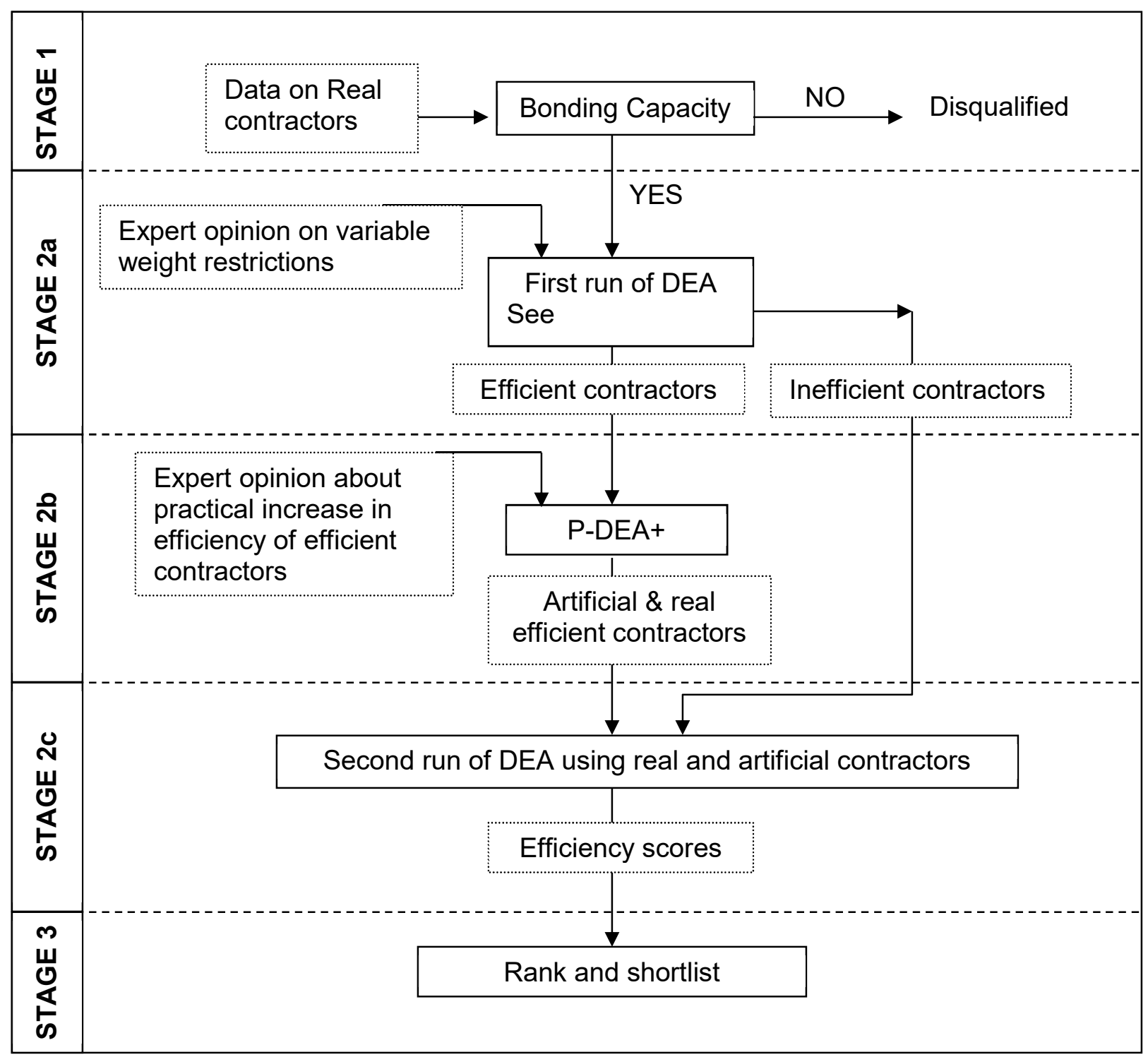

Figure 4: CPM

As stated by Ramani, the original model had four major shortcomings. First, while DEA has the ability to simultaneously handle multiple inputs and outputs, it does not differentiate the relative importance of these variables. The use of weight restrictions would address this issue. The second limitation is the large quantity of units required to run a reliable analysis a minimum of three DMUs for each variable in the model. Thirdly, the efficiency score is relative to the DMU set; while a DMU may be efficient, it might only be the best of a bad lot. Finally, the analysis must be run as a batch process. The development of a practical frontier would address these other issues. Therefore, Stage 2 was modified to incorporate P-DEA.

The model was tested on 10 contracts within a larger project in which prequalification was undertaken using weighted scores. A series of experiments were run, each comparing the results with the weighted scores results, herein referred to as the baseline. The experiments proceeded from the original DEA model by Ramani, DEA with variable weight restrictions, and $\mathrm{P}-\mathrm{DEA}+$ with weight restrictions. It should be noted that the objective was not 
to match the results of the baseline, but to examine the different model results and attempt to justify them.

\section{Data Collection}

Prequalification data were examined from 1998 to 2000 for ten contracts ranging from 3 to 12 millions dollars. Each contract had at least 15 contractor prequalification packages. For brevity, only the results of Contract A will be discussed here. The prequalification package included:

- Completed CCDC-11 form (Contractor's Qualification Statement of the Canadian Construction Document Committee (CCDC 1996). The CCDC-11 contains the contractor's legal structure, financial references, client references, annual value of construction work for the past 5 years, principal projects completed in the past 5 years, similar or related projects completed, major projects underway, and key office and site personnel proposed for the project plus resumes of qualification.

- Resumes of supervisory personnel to be assigned to the project

- Letter of Consent of Surety from a bonding company confirming the contractor's capacity to obtain bid, performance, and payment bonds and the minimum established bonding capacity.

- Certificate of Clearance from the Workplace Safety and Insurance Board (WSIB) stating that the contractor's account with WSIB is not delinquent.

- Current CAD-7, also from WSIB. This value consists of two parts: the cost of accidents, and the frequency of accidents. These are combined into a firm performance index (FPI) ranging between -2 and +1 . A FPI of 1 is the best, indicating that the contractor has had no or relatively few minor accidents. The sector average score is 0 , and a score of -2 is the worst rating. Companies with a FPI between 0 and 1 receive a rebate, while those with a value between 0 and -2 are levied a surcharge (CSAO 2000).

The baseline model is a weighted score system with ten criteria shown in Table 2. The system awards a maximum of 50 points and each criterion has a different possible maximum score. The scores for each contractor are summed, resulting in the prequalification ratings shown in Table 3 . The best possible score is 50 , with most contractors scoring in the $40 \mathrm{~s}$.

Table 2 : Weighted Score System

\begin{tabular}{|c|cll|}
\hline Evaluation Criteria & \multicolumn{2}{|c|}{ Points } \\
\hline \multirow{3}{*}{ Letter of Consent of Surety } & $10=$ & Yes \\
& $0=$ & Not Sufficient \\
$-5=$ & None \\
\hline \multirow{2}{*}{ WSIB Clearance Certificate } & $2=$ & Yes \\
& $0=$ & No Information \\
\hline & $4=$ & Good Standing \\
CAD - 7 Report & $2=$ & Average \\
& $0=$ & Poor or no info. \\
\hline \multirow{3}{*}{ Average Annual Value of } & $6=$ & Over \$5M \\
Construction & $1=$ & \$3 to 5M \\
& $0=$ & Less than $\$ 2 \mathrm{M}$ \\
\hline Related Projects & $10=$ & Good experience \\
(with references) & $5=$ & Some experience \\
& $-10=$ & None or no info provided \\
\hline Key Personnel Assigned to & $5=$ & Good experience \\
Projects & $0=$ & No experience \\
\hline
\end{tabular}




\begin{tabular}{|c|ll|}
\hline \multirow{2}{*}{ Personnel Resumes } & $2=$ & Resumes \\
& $0=$ & None \\
\hline \multirow{3}{*}{ Type of Company } & $4=$ & Corporation \\
& $3=$ & Partnership \\
& $2=$ & Individual \\
\hline \multirow{3}{*}{ Financial References } & $4=$ & Bank \\
& $3=$ & Bonding Co. \\
& $0=$ & None \\
\hline \multirow{2}{*}{ Completed Projects in Last } & $3=4$ or more \\
Five Years & $1=1$ to 3 \\
& $-4=$ & NIL \\
\hline
\end{tabular}

Table 3: Weighted Score Model for Contract A

\begin{tabular}{|c|c|c|c|c|c|c|c|c|c|c|c|}
\hline 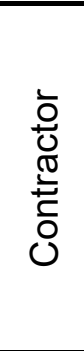 & 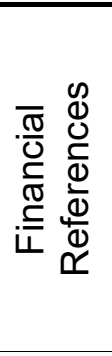 & 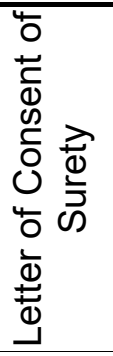 & 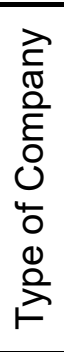 & 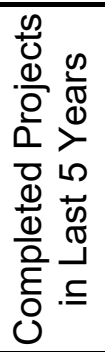 & 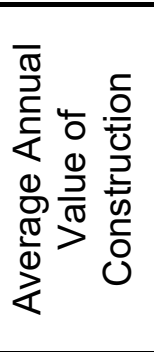 & 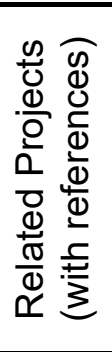 & 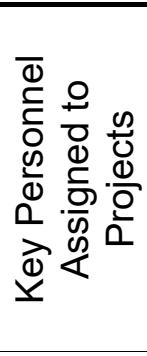 & 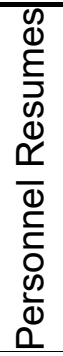 & 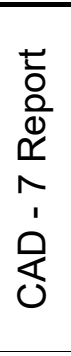 & 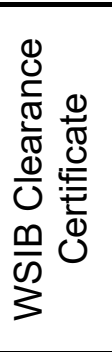 & $\begin{array}{l}0 \\
0 \\
0 \\
\text { क } \\
\overline{0} \\
0 \\
0\end{array}$ \\
\hline A1 & 4 & 10 & 4 & 3 & 6 & 8 & 0 & 0 & 0 & 2 & 37 \\
\hline $\mathrm{A} 2$ & 4 & 10 & 4 & 3 & 0 & 8 & 2 & 2 & 4 & 2 & 39 \\
\hline A3 & 4 & 10 & 4 & 3 & 0 & 9 & 4 & 2 & 4 & 2 & 42 \\
\hline A4 & 4 & 10 & 4 & 3 & 6 & 9 & 4 & 2 & 0 & 0 & 42 \\
\hline A5 & 4 & 10 & 4 & 0 & 5 & 10 & 4 & 2 & 2 & 2 & 43 \\
\hline A6 & 4 & 10 & 4 & 3 & 1 & 9 & 4 & 2 & 4 & 2 & 43 \\
\hline A7 & 4 & 10 & 4 & 3 & 6 & 5 & 4 & 2 & 4 & 2 & 44 \\
\hline A8 & 4 & 10 & 4 & 3 & 5 & 10 & 4 & 2 & 4 & 2 & 48 \\
\hline A9 & 4 & 10 & 4 & 3 & 6 & 10 & 4 & 2 & 0 & 2 & 45 \\
\hline A10 & 4 & 10 & 4 & 3 & 6 & 5 & 4 & 2 & 4 & 2 & 44 \\
\hline A11 & 4 & 10 & 4 & 3 & 6 & 5 & 4 & 2 & 4 & 2 & 44 \\
\hline A12 & 4 & 10 & 4 & 3 & 6 & 5 & 4 & 2 & 4 & 2 & 44 \\
\hline A13 & 4 & 10 & 2 & 3 & 5 & 10 & 2 & 2 & 4 & 2 & 44 \\
\hline A14 & 4 & 10 & 4 & 3 & 6 & 5 & 4 & 2 & 4 & 2 & 44 \\
\hline A15 & 4 & 10 & 4 & 3 & 5 & 10 & 4 & 2 & 0 & 2 & 44 \\
\hline A16 & 4 & 10 & 4 & 3 & 5 & 9 & 0 & 0 & 4 & 2 & 41 \\
\hline
\end{tabular}

Weighted score prequalification models have shortcomings. In this case, there were some subjective decisions made in the assignment of scores to each contractor. Where data were missing, the decision maker would complete the scoring using their knowledge of the local industry. While it was useful for the project management team, it made the process less defensible. Further, an excellent score in one factor could overshadow a poor score in another factor. For example, consider contractors A-7 and A-10 to A-15. They all received a score of 44 points. They received the same number of points for personnel resumes, financial references, completed projects, letter of Consent of Surety, and, WSIB Clearance certificate. Contractor A-15 received the lowest rating for safety, but instead made great points in related projects. Are these equivalent? A-13 also received excellent points in related projects, but lost 
points in key personnel and type of company. Although the company has experience with the specific type of project, would it not be equally or more important that the key persons assigned to the project have similarly excellent experience? Further, there appears to be redundancy in Key Personnel and Personnel Resumes. Finally, as in this case, points are often assigned in a step function. For example, if the company does $\$ 2.8 \mathrm{M}$ of construction business a year, and another company does $\$ 3.2 \mathrm{M}$, one could argue that those three points do not represent as much value to the project as the two points given for WSIB clearance certificate.

Particularly, it is noteworthy that criteria Financial References, Letter of Consent of Surety, Type of Company, Completed Projects in Last 5 Years, and WSIB Clearance Certificates are not very discriminating. Financial References, Letter of Consent of Surety, and WSIB Clearance Certificate are external documents and based on their importance, could be mandatory thereby eliminating them from the evaluation process if the document is missing.

\section{Selection of Operational Variables}

After considerations of the top criteria identified in Table 1, the availability of data, expert opinion on the relevance of the factors, and the criteria used in the weighted scores system, five contractor prequalification criteria shown in Figure 5 were selected as the DEA variables. The assignment of variables as an operational input or output was based on the DEA concept that inputs are variables that you want to minimize, and outputs of an operation should be maximized. Expert opinion for the weight restrictions and efficiency improvements were also collected. The experts included two senior project managers representing the owner and a senior project manager from a large construction company. The variables used for this project may not be relevant for all other projects. The criteria used for prequalification should be customized to address the local market conditions, the owner's objectives, and the project's characteristics. Then, the relative importance of the variables is established by the weights assigned to them.

- Safety records (SR) - The FPI from the CAD-7 documents was used; however, DEA requires that all variables be positive. Since this variable was going to be an operational input and the goal is to minimize inputs, the equation 4.0-FPI was used to transform the FPI value and meet the constraints of the model.

- Current capacity (CC) - Defined as the contractor's current workload (CWL) plus the proposed project value (PV), divided by the maximum amount of work the contractor had undertaken at any time in the last five years. Unfortunately, data on the maximum amount of work were not available, therefore, the sales history $(\mathrm{SH})$ was used; a factor, $c$, was incorporated to account for the difference between the two, as shown in Equation 6. Fortunately in the BCC model, there is a scale invariance property that allows the variables to be measured in any units and to be scaled by any factor since only the relative scores of the DMUs are calculated (Ali and Seiford 1993). In this case, $c=1$ as it didn't matter what value was used, and arbitrarily assigning a value other than one seemed ineffective.

$$
C C=\frac{C W L+P V}{S H} \times c \times 100 \%
$$

- Sales history (SH) - The average annual construction value achieved by the contractor in the last 5 years.

- Related work experience (RE) - The summation of the monetary values of all related projects provided in the contractor's statement. 
- Employee experience (EE) - From the resumes submitted by the contractor, the years of experience of the key supervisory personnel assigned to the project were summed to indicate the management resource of the contractor.

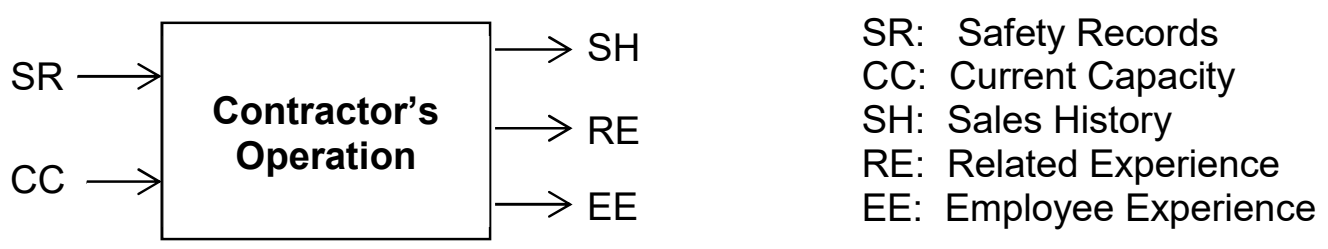

Figure 5: CPM Prequalification Variables

The contractor data are shown in Table 4. Correlation analysis was performed on the variables for each contract, and with the combination of data from all 10 contracts. It was found that the variables have low correlation; the highest correlation coefficient was 0.358 between Related Experience and Sales History. The five variables were therefore not redundant and reasonably representative of the contractors.

Table 4 : Contractor Data

\begin{tabular}{rrrrrr}
\hline & \multicolumn{3}{c}{ Inputs } & \multicolumn{3}{c}{ Outputs } \\
\cline { 2 - 6 } & \multicolumn{1}{c}{ SR } & \multicolumn{1}{c}{ CC } & \multicolumn{1}{c}{ RE } & \multicolumn{1}{c}{ SH } & \multicolumn{1}{c}{ EE } \\
\hline A1 & 2.90 & 62.01 & 2.72 & 7.52 & 96 \\
A2 & 1.01 & 275.84 & 1.46 & 1.73 & 65 \\
A3 & 1.00 & 288.78 & 0.45 & 1.78 & 38 \\
A4 & 4.00 & 95.87 & 11.75 & 10.00 & 90 \\
A5 & 2.05 & 93.36 & 7.38 & 6.48 & 97 \\
A6 & 1.00 & 241.88 & 4.61 & 2.86 & 58 \\
A7 & 1.42 & 38.30 & 38.32 & 65.80 & 127 \\
A8 & 1.01 & 161.75 & 9.40 & 3.78 & 190 \\
A9 & 4.00 & 204.92 & 1.52 & 6.10 & 128 \\
A10 & 1.70 & 62.93 & 202.32 & 167.16 & 95 \\
A11 & 2.04 & 52.45 & 1.74 & 25.80 & 157 \\
A12 & 1.41 & 54.31 & 11.33 & 27.60 & 200 \\
A13 & 1.00 & 189.32 & 2.91 & 3.96 & 106 \\
A14 & 1.29 & 137.73 & 83.40 & 47.83 & 94 \\
A15 & 4.00 & 219.32 & 2.34 & 4.40 & 34 \\
A16 & 1.16 & 109.43 & 48.40 & 3.20 & 84 \\
\hline
\end{tabular}

\section{ANALYSIS RESULTS}

The DEA software used to run the model was the Efficiency Measurement System (EMS) developed at University of Dortmund, Germany. EMS is capable of handling DEA problems with over 5000 DMUs and 40 variables. The BCC model was run on all 10 contracts; both input and output-orientation were investigated. Only the output-oriented results will be discussed here. 
The contractors that did not meet the bonding requirements were excluded from further analysis. The DEA model was first run without any restriction imposed on the variable weights. Then, the relative importance of the weights assessed by the experts were converted into constraints as ratios and added to the basic DEA model, and the analysis was run again, this time with more consistency in the weights. The mathematical forms of the weight constraints are:

$$
\frac{v_{1}(\text { SafetyRecords })}{v_{2}(\text { CurrentCapacity })}=\frac{4}{3}, \frac{u_{1}(\text { RelatedExperience })}{u_{2}(\text { SalesHistory })}=\frac{20}{6}, \frac{u_{1}(\text { RelatedExperience })}{u_{3}(\text { EmployeeExperience })}=\frac{20}{7}
$$

Ranking comparison for Contract $A$ between the weighted scores and the DEA models is presented in Table 5. Comparing the results, the number of efficient DMUs decreased significantly from seven in the run without weight restrictions to only two with weight restrictions, indicating the improved discrimination power of DEA with the weight restrictions. This trend was observed in all ten contracts. Some differences in rank are worth discussing, particularly DMUs A7 to A10, shown as the top four in Table 5. The baseline model resulted in top scores for contractors A8 and A9, but the DEA weight restricted model placed those two as \#7 and \#8 respectively. The primary difference between the two evaluation methods is that step functions are generally used in weighted score systems to convert the actual values of the evaluation variables into scores (as shown in Table 2) whereas continuous values are used directly in DEA models. DMU A9 lost 4 points in the weighted score due to a poor safety rating, but made up for it in the related projects category. One should be concerned that a contractor with a poor safety record was ranked \#2.

Table 5: Rank Comparison- Output Orientation

\begin{tabular}{ccccccc}
\hline \multirow{2}{*}{ Contractors } & \multicolumn{2}{c}{ Weighted Score } & \multicolumn{2}{c}{ Stage 2a } & \multicolumn{2}{c}{ Stage 2a } \\
& \multicolumn{2}{c}{ Max 50 Points } & No Weight Restrictions & Weight Restrictions \\
\cline { 2 - 7 } & Score & Rank & Score & Rank & Score & Rank \\
\hline A8 & 48 & 1 & 1.00 & $1-7$ & 3.71 & 7 \\
A9 & 45 & 2 & 1.56 & 11 & 5.93 & 8 \\
A10 & 44 & $3-9$ & 1.00 & $1-7$ & 1.00 & $1-2$ \\
A7 & 44 & $3-9$ & 1.00 & $1-7$ & 1.00 & $1-2$ \\
A12 & 44 & $3-9$ & 1.00 & $1-7$ & 2.45 & 4 \\
A13 & 44 & $3-9$ & 1.00 & $1-7$ & 6.94 & 11 \\
A14 & 44 & $3-9$ & 1.05 & 8 & 2.19 & 3 \\
A11 & 44 & $3-9$ & 1.22 & 9 & 3.29 & 5 \\
A15 & 44 & $3-9$ & 5.84 & 16 & 18.36 & 15 \\
A6 & 43 & $10-11$ & 1.00 & $1-7$ & 11.09 & 13 \\
A5 & 43 & $10-11$ & 2.04 & 12 & 6.60 & 10 \\
A3 & 42 & $12-13$ & 1.53 & 10 & 20.00 & 16 \\
A4 & 42 & $12-13$ & 2.14 & 14 & 6.18 & 9 \\
A16 & 41 & 14 & 1.00 & $1-7$ & 3.63 & 6 \\
A2 & 39 & 15 & 2.49 & 15 & 11.56 & 14 \\
A1 & 37 & 16 & 2.08 & 13 & 7.41 & 12 \\
\hline
\end{tabular}

That DMUs A7 and A10 were evaluated as efficient indicates that the actual values for the variable Related Projects did not warrant the 5 point jump earned by A8 and A9 as compared to A7 and A10 in the weighted score model. Clearly, the advantage in using the DEA model is that using real values allows the distinctions to be recognized proportionally, and that low scores in one area cannot override a higher score in another category. 


\section{Stage 2b - Creating Artificial Improved DMU}

The objective of this stage is to determine the possible improvement in inputs and outputs of efficient contractors evaluated in Stage $2 a$ and to use this information to create the artificial contractors using P-DEA+. The parameters entered into the model were the possible increase in efficiency of best practice units $(\delta)$, and the allowable ranges of variation of inputs and outputs $\left(L_{x i o} \leq \tilde{x}_{i o} \leq U_{x i o}, L_{y r o} \leq \tilde{y}_{r o} \leq U_{y r o}\right)$. The parameters used are:

$\begin{array}{ll}\delta=0.06 & (1-0.20) * x_{i o} \leq \widetilde{x}_{i o} \leq(1+0.20) * x_{i o} \\ \text { Safety Records: } & (1-0.20) * x_{i o} \leq \widetilde{x}_{i o} \leq(1+0.30) * x_{i o} \\ \text { Current Capacity: } & (1-0.05) * y_{i o} \leq \widetilde{y}_{i o} \leq(1+0.03) * y_{i o} \\ \text { Related Experience: } & (1-0.10) * y_{i o} \leq \widetilde{y}_{i o} \leq(1+0.05) * y_{i o} \\ \text { Sales History: } & (1-0.20) * y_{i o} \leq \widetilde{y}_{i o} \leq(1+0.20) * y_{i o} \\ \text { Employee Experience: } & \end{array}$

The P-DEA+ model was solved for each efficient contractor from Stage 2a with weight restrictions. Excel's solver was used to execute the P-DEA+ linear programming for all ten contracts as the inverse mechanism of EMS, i.e. to determine the new values of inputs and outputs from a maximum efficiency score value by optimizing the weights. The weight restrictions used in Stage 2a were included as constraints. Table 6 presents the results of contract A. The inputs and outputs of new contractors are presented along with the original efficient contractors upon which the new contractors, denoted by N, were based.

Table 6: Inputs and outputs of new contractors

\begin{tabular}{ccccccc}
\hline & Contractor & SR & CC & RE & SH & EE \\
\hline Contract & A7 & 1.42 & 38.30 & 36.40 & 59.22 & 101.6 \\
A & A7N & 1.17 & 34.72 & 38.32 & 65.8 & 127 \\
& A10 & 1.70 & 62.93 & 202.32 & 167.16 & 95 \\
& A10N & 1.04 & 60.83 & 208.39 & 175.52 & 114 \\
\hline
\end{tabular}

\section{Stage 2c - Establishing the Practical Frontier}

The objective of this stage was to define the practical frontier by running the DEA model again with both the original and the artificial contractors. Analysis was done on all ten contracts with the same weight restrictions as in the last stage. Table 7 shows Stage $2 \mathrm{c}$ results for contract A. Included are the efficiency scores of both the real and artificial contractors, and the weights used in the analysis. The practical frontier is believed to reflect the industry's standard in the Southern Ontario region since the contracts under evaluation were relatively large and the contractors involved in the prequalification are representative of the regional market.

Assuming that the top nine contractors in the weighted scores evaluation would have been prequalified, it is of interest to examine how they performed at the various stages of the CPM. In bold are shown the top nine ranked contractors in each evaluation model. As noted earlier, A13 and A15 were questions whether they should be in the top nine contractors. The DEA models with weight restrictions captured these anomalies, and placed these two contractors at $11^{\text {th }}$ and $15^{\text {th }}$ places, respectively. In addition, all DEA models would have brought A16 into the top nine, and the weight restricted DEA would have included A4. 
Table 7: Stage 2c: Contract A Results

\begin{tabular}{ccccccc}
\hline \multirow{2}{*}{ DMU } & Efficiency & \multicolumn{5}{c}{ Variable Weights } \\
\cline { 3 - 7 } & Score & SR & CC & RE & SH & EE \\
\hline A7N & 1.00 & 0.037 & 0.028 & 0.011 & 0.003 & 0.004 \\
A10N & 1.00 & 0.021 & 0.016 & 0.003 & 0.001 & 0.001 \\
A10 & 1.05 & 0.020 & 0.015 & 0.003 & 0.001 & 0.001 \\
A7 & 1.17 & 0.033 & 0.025 & 0.010 & 0.003 & 0.003 \\
A14 & 2.30 & 0.055 & 0.007 & 0.008 & 0.002 & 0.003 \\
A12 & 2.72 & 0.024 & 0.018 & 0.011 & 0.003 & 0.004 \\
A11 & 3.66 & 0.024 & 0.018 & 0.016 & 0.005 & 0.005 \\
A16 & 3.82 & 0.019 & 0.009 & 0.013 & 0.004 & 0.004 \\
A8 & 3.91 & 0.010 & 0.006 & 0.013 & 0.004 & 0.005 \\
A9 & 6.25 & 0.045 & 0.004 & 0.021 & 0.006 & 0.007 \\
A4 & 6.51 & 0.020 & 0.010 & 0.022 & 0.006 & 0.008 \\
A5 & 6.95 & 0.035 & 0.010 & 0.023 & 0.007 & 0.008 \\
A13 & 7.31 & 0.010 & 0.005 & 0.024 & 0.007 & 0.008 \\
A1 & 7.80 & 0.026 & 0.015 & 0.026 & 0.008 & 0.009 \\
A6 & 11.68 & 0.539 & 0.002 & 0.039 & 0.012 & 0.014 \\
A2 & 12.17 & 0.015 & 0.004 & 0.040 & 0.012 & 0.014 \\
A15 & 19.34 & 0.248 & 0.001 & 0.064 & 0.019 & 0.022 \\
A3 & 21.07 & 0.052 & 0.003 & 0.070 & 0.021 & 0.025 \\
\hline
\end{tabular}

Table 8: Comparison of Model Results

\begin{tabular}{|c|c|c|c|c|c|c|c|c|}
\hline \multirow[b]{2}{*}{ Contractors } & \multicolumn{2}{|c|}{$\begin{array}{l}\text { Weighted Scores } \\
\text { Max } 50 \text { Points }\end{array}$} & \multicolumn{2}{|c|}{$\begin{array}{c}\text { Stage 2a } \\
\text { No Weight } \\
\text { Restrictions }\end{array}$} & \multicolumn{2}{|c|}{$\begin{array}{c}\text { Stage 2a } \\
\text { Weight Restrictions }\end{array}$} & \multicolumn{2}{|c|}{$\begin{array}{c}\text { Stage 2c } \\
\text { Practical Frontier } \\
\text { with Weight Restr. }\end{array}$} \\
\hline & Score & Rank & Score & Rank & Score & Rank & Score & Rank \\
\hline $\mathrm{A} 8$ & 48 & 1 & 1.00 & $1-7$ & 3.71 & 7 & 3.91 & 7 \\
\hline A9 & 45 & 2 & 1.56 & 11 & 5.93 & 8 & 6.25 & 8 \\
\hline A10 & 44 & $3-9$ & 1.00 & $1-7$ & 1.00 & $1-2$ & 1.05 & 1 \\
\hline A7 & 44 & $3-9$ & 1.00 & $1-7$ & 1.00 & $1-2$ & 1.17 & 2 \\
\hline A14 & 44 & $3-9$ & 1.05 & 8 & 2.19 & 3 & 2.30 & 3 \\
\hline A12 & 44 & 3-9 & 1.00 & $1-7$ & 2.45 & 4 & 2.72 & 4 \\
\hline A11 & 44 & 3-9 & 1.22 & 9 & 3.29 & 5 & 3.66 & 5 \\
\hline A13 & 44 & 3-9 & 1.00 & $1-7$ & 6.94 & 11 & 7.31 & 11 \\
\hline A15 & 44 & 3-9 & 5.84 & 16 & 18.36 & 15 & 19.34 & 15 \\
\hline A6 & 43 & $10-11$ & 1.00 & $1-7$ & 11.09 & 13 & 11.68 & 13 \\
\hline A5 & 43 & $10-11$ & 2.04 & 12 & 6.60 & 10 & 6.95 & 10 \\
\hline A3 & 42 & $12-13$ & 1.53 & 10 & 20.00 & 16 & 21.07 & 16 \\
\hline A4 & 42 & $12-13$ & 2.14 & 14 & 6.18 & 9 & 6.51 & 9 \\
\hline A16 & 41 & 14 & 1.00 & $1-7$ & 3.63 & 6 & 3.82 & 6 \\
\hline $\mathrm{A} 2$ & 39 & 15 & 2.49 & 15 & 11.56 & 14 & 12.17 & 14 \\
\hline A1 & 37 & 16 & 2.08 & 13 & 7.41 & 12 & 7.80 & 12 \\
\hline
\end{tabular}

\section{CONCLUSIONS}

Prequalifying contractors in a construction project is a not a simple task since the process involves comparing units with multiple criteria and qualitative information. Data envelopment analysis, with its ability to measure the relative performance of organizational units that have multiple inputs and outputs, has been demonstrated as a feasible solution to the contractor prequalification problem. A 3-stage methodology that is able to create best- 
practice benchmarks (practical frontiers) for comparing contractors for a specific project type was established.

The CPM framework could be extremely useful to major owners that manage large annual budgets in construction, such as Departments/Ministries of Transportation, petrochemical facilities, and large municipalities, where the prequalification process is often undertaken by these organizations just once per year. The variables used by each owner would be customized to meet their needs. A standard practical frontier could be useful as a regional performance benchmark against which contractors could measure themselves and identify possible performance targets. And, because they are comparing themselves to artificial DMUs, confidentiality is maintained. The model variables provided here may not work for every project if the practical frontier is used for many, different projects. The authors strongly believe that this methodology has many more advantages than disadvantages over the current systems used today, particularly for large buyers of construction.

\section{ACKNOWLEDGEMENTS}

The authors respectfully acknowledge and enthusiastically appreciate the financial and research support of the Greater Toronto Airports Authority and MGP Project Managers in conjunction with NSERC Industrial Oriented Research Grant \# 216754-98 in the development of this model.

\section{REFERENCES}

AbouRizk, S.M., and Chehayeb, N.N. 1995. Hypertext decision support model for contractor prequalification. Microcomputers in Civil Engineering. 10: $111-121$.

Ali, A.I. and Seiford, L.M. 1993. The mathematical programming approach to efficiency analysis. The Measurement of Productive Efficiency: Techniques and Applications. Fried, H., Lovell, C. A. Knox, and Thore, Sten (editors). Oxford University Press. London. pp. $120-159$.

Banker, R.D., Charnes, A., and Cooper, W.W. 1984. Some models for estimating technical and scale inefficiencies in data envelopment analysis. Management Science. 30: 1078 - 1092.

Bubshait, A.A. and Al-Gobali, K.H. 1996. Contractor prequalification in Saudi Arabia. Journal of Management in Engineering. 12: 50 - 54.

CCDC. 1996. Standard construction document - CCDC-11 - 1996. Canadian Construction Documents Committee. Ottawa, Ontario.

Charnes, A., Cooper, W.W., and Rhodes, E.L. 1978. Measuring the efficiency of decision making units. European Journal of Operations Research. 2: $429-444$.

Charnes, A., Cooper, W.W., Lewin, A.Y., and Seiford, L.M. 1994. Introduction and basic DEA models. Data Envelopment Analysis: Theory, Methodology and Applications. Charnes et al. Editors. Kluwer Academic Publishers. pp. 3 - 47.

CSAO. 2000. CAD-7 Experience rating for Ontario construction. Construction Safety Association of Ontario, third revised edition. Etobicoke, Ontario. M9W 5M7.

Elton, D.J., Juang, C.H. and Russell, J.S. 1994. Contractor prequalification using fuzzy sets. Civil Engineering Systems. 11: 1- 17.

Gong, X. 1999. Contractor prequalification process. M. Eng. Project. Department of Civil Engineering, University of Toronto, Toronto, ON M5S $1 \mathrm{~A} 4$.

Hanna, A. S., Russell, J. S., Taha, M. A., and Park, S. C. 1997. Application of neural networks to owner-contractor prequalification. Artificial Neural Networks for Civil Engineers: Fundamentals and Applications. ASCE, New York, NY pp. 124-136

Holt, Gary D. 1996. Applying cluster analysis to construction contractor classification. Building and Environment. 31: 557 - 568. 
Juang, C. H., Burati, J. L., Kalindindi, S. N. 1987. A fuzzy system for bid proposal evaluation using microcomputers. Civil Engineering Systems. 4: $124-130$.

Liston, J.W., 1994. Prequalification of contractors construction and management recent advances. Australia. pp. 396-411

Paulson, B.C. Jr., and Aki, T. 1980. Construction management in Japan. Journal of the Construction Division. 106: 281-296

Ramani, J. 2000. Reducing the bias in contractor prequalification using data envelopment analysis. MASc. Dissertation. Department of Civil Engineering, University of Toronto, Canada.

Russell, J.S., and Skibniewski, M.J. 1990. QUALIFIER - 1: contractor prequalification model. Journal of Computing in Civil Engineering. 4: 77 - 90.

Russell, J.S., Skibniewski, M.J., and Cozier, D.R. 1990. QUALIFIER - 2: knowledge-based system for contractor prequalification. Journal of Construction Engineering and Management. 116: $157-171$.

Sowlati, T., 2001. Establishing the practical frontier in data envelopment analysis. PhD. Dissertation. Department of Mechanical and Industrial Engineering, University of Toronto, Canada.

Tran, V.H.Q. 2002. Practical frontier in construction prequalification using data envelopment analysis. MASc Dissertation, Department of Civil Engineering, University of Toronto, Canada. 